Bull. Korean Math. Soc. 49 (2012), No. 4, pp. 799-813

http://dx.doi.org/10.4134/BKMS.2012.49.4.799

\title{
WEAK AND STRONG CONVERGENCE FOR QUASI-NONEXPANSIVE MAPPINGS IN BANACH SPACES
}

\author{
GANG Eun KIM
}

\begin{abstract}
In this paper, we first show that the iteration $\left\{x_{n}\right\}$ defined by $x_{n+1}=P\left(\left(1-\alpha_{n}\right) x_{n}+\alpha_{n} T P\left[\beta_{n} T x_{n}+\left(1-\beta_{n}\right) x_{n}\right]\right)$ converges strongly to some fixed point of $T$ when $E$ is a real uniformly convex Banach space and $T$ is a quasi-nonexpansive non-self mapping satisfying Condition $\mathbf{A}$, which generalizes the result due to Shahzad [11]. Next, we show the strong convergence of the Mann iteration process with errors when $E$ is a real uniformly convex Banach space and $T$ is a quasi-nonexpansive self-mapping satisfying Condition $\mathbf{A}$, which generalizes the result due to Senter-Dotson [10]. Finally, we show that the iteration $\left\{x_{n}\right\}$ defined by $x_{n+1}=\alpha_{n} S x_{n}+\beta_{n} T\left[\alpha_{n}^{\prime} S x_{n}+\beta_{n}^{\prime} T x_{n}+\gamma_{n}^{\prime} v_{n}\right]+\gamma_{n} u_{n}$ converges strongly to a common fixed point of $T$ and $S$ when $E$ is a real uniformly convex Banach space and $T, S$ are two quasi-nonexpansive self-mappings satisfying Condition D, which generalizes the result due to Ghosh-Debnath $[3]$.
\end{abstract}

\section{Introduction}

Let $E$ be a real uniformly convex Banach space and let $C$ be a nonempty closed convex subset of $E$. Then a mapping $T$ from $C$ into $E$ is called nonexpansive if $\|T x-T y\| \leq\|x-y\|$ for all $x, y \in C$. A mapping $T$ from $C$ into $E$ is also called quasi-nonexpansive if the set $F(T)$ of fixed points of $T$ is nonempty and $\|T x-y\| \leq\|x-y\|$ for all $x \in C$ and $y \in F(T)$. For a mapping $T$ of $C$ into itself, we consider the following iteration scheme: $x_{1} \in C$,

$$
x_{n+1}=\left(1-\alpha_{n}\right) x_{n}+\alpha_{n} T\left[\beta_{n} T x_{n}+\left(1-\beta_{n}\right) x_{n}\right]
$$

for all $n \geq 1$, where $\left\{\alpha_{n}\right\}$ and $\left\{\beta_{n}\right\}$ are real sequences in $[0,1]$. Such an iteration scheme was introduced by Ishikawa [5]; see also Mann [7]. Let $C$ be a nonexpansive retract of $E$. For a mapping $T$ from $C$ into $E$, we also consider the following iteration scheme (Shahzad [11]): $x_{1} \in C$,

$$
x_{n+1}=P\left(\left(1-\alpha_{n}\right) x_{n}+\alpha_{n} T P\left[\beta_{n} T x_{n}+\left(1-\beta_{n}\right) x_{n}\right]\right)
$$

Received April 19, 2011; Revised October 4, 2011.

2010 Mathematics Subject Classification. 47H05, 47H10.

Key words and phrases. weak and strong convergence, fixed point, Opial's condition, Condition A, Condition D, quasi-nonexpansive mapping. 
for all $n \geq 1$, where $\left\{\alpha_{n}\right\}$ and $\left\{\beta_{n}\right\}$ are real sequences in $[0,1]$ and $P$ is a nonexpansive retraction of $E$ onto $C$. If $T$ is a self-mapping, then (2) reduces to an iteration scheme (1). For two mappings $S, T$ of $C$ into itself, we also consider a more general iterative scheme of the type (cf., Ghosh-Debnath [3], $\mathrm{Xu}[13])$ emphasizing the randomness of errors as follows:

$$
\begin{aligned}
& x_{1} \in C, \\
& x_{n+1}=\alpha_{n} S x_{n}+\beta_{n} T y_{n}+\gamma_{n} u_{n}, \\
& y_{n}=\alpha_{n}^{\prime} S x_{n}+\beta_{n}^{\prime} T x_{n}+\gamma_{n}^{\prime} v_{n},
\end{aligned}
$$

where $\left\{\alpha_{n}\right\},\left\{\beta_{n}\right\},\left\{\gamma_{n}\right\},\left\{\alpha_{n}^{\prime}\right\},\left\{\beta_{n}^{\prime}\right\},\left\{\gamma_{n}^{\prime}\right\}$ are real sequences in [0,1] and $\left\{u_{n}\right\}$, $\left\{v_{n}\right\}$ are two bounded sequences in $C$ such that

(i) $\alpha_{n}+\beta_{n}+\gamma_{n}=\alpha_{n}^{\prime}+\beta_{n}^{\prime}+\gamma_{n}^{\prime}=1$ for all $n \geq 1$,

(ii) $\sum_{n=1}^{\infty} \gamma_{n}<\infty$ and $\sum_{n=1}^{\infty} \gamma_{n}^{\prime}<\infty$.

If $S=I$, the identity mapping and $\gamma_{n}=\gamma_{n}^{\prime}=0$ for all $n \geq 1$, then (3) reduces to an iteration scheme (1), while setting $S=I, \beta_{n}^{\prime}=0$ and $\gamma_{n}^{\prime}=0$ for all $n \geq 1$ reduces to the Mann iteration process with errors which is a generalized case of the Mann iteration process. Recently, Shahzad [11] proved that if $E$ is a real uniformly convex Banach space, and $C$ is a nonempty closed convex subset of $E$ which is also a nonexpansive retract of $E$, and $T: C \rightarrow E$ is a nonexpansive mapping with $F(T) \neq \emptyset$, and $T$ satisfies Condition $\mathbf{A}$, then for any $x_{1}$ in $C$, the sequence $\left\{x_{n}\right\}$ defined by (2) converges strongly to some fixed point of $T$ under the assumption that $\left\{\alpha_{n}\right\}$ and $\left\{\beta_{n}\right\}$ are such that $0<a \leq \alpha_{n}, \beta_{n} \leq b<1$ for all $n \geq 1$ and some $a, b \in(0,1)$. On the other hand, Senter-Dotson [10] proved that if $E$ is a real uniformly convex Banach space, and $C$ is a nonempty closed convex subset of $E$, and $T: C \rightarrow C$ is a quasi-nonexpansive mapping satisfying Condition $\mathbf{A}$, then for any $x_{1} \in C$, the sequence $\left\{x_{n}\right\}$ defined by $x_{n+1}=\left(1-\alpha_{n}\right) x_{n}+\alpha_{n} T x_{n}$ converges strongly to some fixed point of $T$ under the assumption that $\left\{\alpha_{n}\right\}$ in $[0,1]$ is chosen so that $\alpha_{n} \in[a, b]$ for all $n \geq 1$ and some $a, b \in(0,1)$. Ghosh-Debnath [3] proved that if $E$ is a real uniformly convex Banach space and $C$ is a nonempty closed convex subset of $E$ and $T, S: C \rightarrow C$ are two quasi-nonexpansive mappings, and $T, S$ satisfy Condition C with $F(T) \bigcap F(S) \neq \emptyset$, then for any $x_{1}$ in $C$, the sequence $\left\{x_{n}\right\}$ defined by $x_{n+1}=\left(1-\alpha_{n}\right) S x_{n}+\alpha_{n} T\left[\left(1-\beta_{n}\right) S x_{n}+\beta_{n} T x_{n}\right]$ converges strongly to a common fixed point of $T$ and $S$ under the assumption that $\left\{\alpha_{n}\right\}$ and $\left\{\beta_{n}\right\}$ are such that $0<a \leq \alpha_{n} \leq b<1,0 \leq \beta_{n} \leq b<1$ for all $n \geq 1$ and some $a, b \in(0,1)$, which generalized the result due to M. Maiti and M. K. Ghosh [6].

In this paper, we first prove that the iteration $\left\{x_{n}\right\}$ defined by (2) converges strongly to some fixed point of $T$ when $E$ is a real uniformly convex Banach space and $T$ is a quasi-nonexpansive non-self mapping satisfying Condition $\mathbf{A}$, which generalizes the result due to Shahzad [11]. Next, we prove the strong convergence of the Mann iteration process with errors when $E$ is a real uniformly convex Banach space and $T$ is a quasi-nonexpansive self-mapping satisfying Condition A, which generalizes the result due to Senter-Dotson [10]. 
Finally, we prove that the iteration $\left\{x_{n}\right\}$ defined by (3) converges strongly to a common fixed point of $T$ and $S$ when $E$ is a real uniformly convex Banach space and $T, S$ are two quasi-nonexpansive self-mappings satisfying Condition D, which generalizes the result due to Ghosh-Debnath [3].

\section{Preliminaries}

Throughout this paper, we denote by $E$ a real Banach space. Let $C$ be a nonempty closed convex subset of $E$ and let $T$ be a mapping from $C$ into $E$. Then we denote by $F(T)$ the set of all fixed points of $T$, i.e., $F(T)=\{x \in$ $C: T x=x\}$. A subset $C$ of $E$ is said to be a retract of $E$ if there exists a continuous mapping $P: E \rightarrow C$ such that $P x=x$ for all $x \in C$. A mapping $P: E \rightarrow E$ is said to be a retraction if $P^{2}=P$. A Banach space $E$ is said to be uniformly convex if the modulus of convexity $\delta_{E}=\delta_{E}(\epsilon), 0<\epsilon \leq 2$, of $E$ defined by

$$
\delta_{E}(\epsilon)=\inf \left\{1-\frac{\|x+y\|}{2}: x, y \in E,\|x\| \leq 1,\|y\| \leq 1,\|x-y\| \geq \epsilon\right\}
$$

satisfies the inequality $\delta_{E}(\epsilon)>0$ for every $\epsilon \in(0,2]$. When $\left\{x_{n}\right\}$ is a sequence in $E$, then $x_{n} \rightarrow x\left(x_{n} \rightarrow x\right)$ will denote strong (weak) convergence of the sequence $\left\{x_{n}\right\}$ to $x$. A mapping $T: C \rightarrow E$ is said to be demiclosed with respect to $y \in E[1]$ if for any sequence $\left\{x_{n}\right\}$ in $C$, it follows from $x_{n} \rightarrow x$ and $T x_{n} \rightarrow y$ that $x \in C$ and $T(x)=y$. If $I-T$ is demiclosed at zero, i.e., for any sequence $\left\{x_{n}\right\}$ in $C$, the conditions $x_{n} \rightarrow x$ and $x_{n}-T x_{n} \rightarrow 0$ imply $x-T x=0$. A Banach space $E$ is said to satisfy Opial's condition [8] if for any sequence $\left\{x_{n}\right\}$ in $E, x_{n} \rightarrow x$ implies that

$$
\limsup _{n \rightarrow \infty}\left\|x_{n}-x\right\|<\limsup _{n \rightarrow \infty}\left\|x_{n}-y\right\|
$$

for all $y \in E$ with $y \neq x$. All Hilbert spaces and $l^{p}(1<p<\infty)$ satisfy Opial's condition, while $L^{p}$ with $1<p \neq 2<\infty$ do not.

Condition 1 ([10]). A mapping $T: C \rightarrow E$ with $F(T) \neq \emptyset$ is said to satisfy Condition $\mathbf{A}$ if there exists a nondecreasing function $f:[0, \infty) \rightarrow[0, \infty)$ with $f(0)=0$ and $f(r)>0$ for all $r \in(0, \infty)$ such that

$$
\|x-T x\| \geq f(d(x, F(T)))
$$

for all $x \in C$, where $d(x, F(T))=\inf _{z \in F(T)}\|x-z\|$.

Condition $2([6])$. A mapping $T: C \rightarrow C$ with $F(T) \neq \emptyset$ is said to satisfy Condition $\mathbf{B}$ if there exists a nondecreasing function $f:[0, \infty) \rightarrow[0, \infty)$ with $f(0)=0$ and $f(r)>0$ for all $r \in(0, \infty)$ such that

$$
\|x-T y\| \geq f(d(x, F(T)))
$$

for all $x \in C$ with $y=(1-t) x+t T x$, where $0 \leq t \leq \beta<1$ and $d(x, F(T))=$ $\inf _{z \in F(T)}\|x-z\|$. 
Condition 3 ([3]). Two mappings $T, S: C \rightarrow C$ are said to satisfy Condition $\mathbf{C}$ if there exists a nondecreasing function $f:[0, \infty) \rightarrow[0, \infty)$ with $f(0)=0$ and $f(r)>0$ for all $r \in(0, \infty)$ such that

$$
\|S x-T y\| \geq f(d(x, \mathbf{F}))
$$

for all $x, y \in C$ with $y=(1-t) S x+t T x$, where $0 \leq t \leq \beta<1, \mathbf{F}=$ $F(T) \bigcap F(S) \neq \emptyset$ and $d(x, \mathbf{F})=\inf _{z \in \mathbf{F}}\|x-z\|$.

Condition 4. Two mappings $T, S: C \rightarrow C$ are said to satisfy Condition D if there exists a nondecreasing function $f:[0, \infty) \rightarrow[0, \infty)$ with $f(0)=0$ and $f(r)>0$ for all $r \in(0, \infty)$ such that

$$
\|S x-T y\| \geq f(d(x, \mathbf{F}))
$$

for all $x, y \in C$ with $y=\alpha S x+\beta T x+\gamma v$ for all $v \in C$, where $0<a \leq \alpha \leq 1$, $0 \leq \beta, \gamma \leq b<1$ with $\alpha+\beta+\gamma=1, \mathbf{F}=F(T) \bigcap F(S) \neq \emptyset$ and $d(x, \mathbf{F})=$ $\inf _{z \in \mathbf{F}}\|x-z\|$.

If we set $\gamma=0$, then Condition $\mathbf{D}$ becomes identical with Condition $\mathbf{C}$, while setting $S=I$ and $\gamma=0$ becomes identical with Condition B.

\section{Weak and strong convergence theorems}

We first begin with the following lemma.

Lemma 1 ([9]). Let $E$ be a uniformly convex Banach space, $0<b \leq t_{n} \leq$ $c<1$ for all $n \geq 1$ and some $b, c \in(0,1)$ and some $a \geq 0$. Suppose that $\left\{x_{n}\right\}_{n=1}^{\infty}$ and $\left\{y_{n}\right\}_{n=1}^{\infty}$ are sequences of $E$ such that $\lim _{n p_{n \rightarrow \infty}}\left\|x_{n}\right\| \leq a$, $\lim \sup _{n \rightarrow \infty}\left\|y_{n}\right\| \leq a$, and $\lim _{n \rightarrow \infty}\left\|t_{n} x_{n}+\left(1-t_{n}\right) y_{n}\right\|=a$. Then

$$
\lim _{n \rightarrow \infty}\left\|x_{n}-y_{n}\right\|=0 \text {. }
$$

Lemma 2 ([4]). Let $E$ be a uniformly convex Banach space. Let $x, y \in E$. If $\|x\| \leq 1,\|y\| \leq 1$, and $\|x-y\| \geq \epsilon>0$, then $\|\lambda x+(1-\lambda) y\| \leq 1-2 \lambda(1-\lambda) \delta(\epsilon)$ for $\lambda$ with $0 \leq \lambda \leq 1$.

Lemma $3([12])$. Let $\left\{a_{n}\right\}$ and $\left\{b_{n}\right\}$ be sequences of nonnegative real numbers such that $\sum_{n=1}^{\infty} b_{n}<\infty$ and

$$
a_{n+1} \leq a_{n}+b_{n}
$$

for all $n \geq 1$. Then $\lim _{n \rightarrow \infty} a_{n}$ exists.

Our Theorem 1 carries over Theorem 3.3 of Shahzad [11] to a quasi-nonexpansive mapping.

Theorem 1. Let $E$ be a uniformly convex Banach space, and let $C$ be a nonempty closed convex subset of $E$ which is also a nonexpansive retract of $E$, and let $T: C \rightarrow E$ be a quasi-nonexpansive mapping. Suppose that for any $x_{1}$ in $C$, the sequence $\left\{x_{n}\right\}$ is defined by (2), where $\left\{\alpha_{n}\right\}$ and $\left\{\beta_{n}\right\}$ are chosen so that $0<a \leq \alpha_{n}, \beta_{n} \leq b<1$ for all $n \geq 1$ and some $a, b \in(0,1)$. Then $\lim _{n \rightarrow \infty}\left\|T x_{n}-x_{n}\right\|=0$. 
Proof. For any $z \in F(T)$, since

$$
\begin{aligned}
\left\|x_{n+1}-z\right\| & =\left\|P\left(\left(1-\alpha_{n}\right) x_{n}+\alpha_{n} T P\left[\beta_{n} T x_{n}+\left(1-\beta_{n}\right) x_{n}\right]\right)-P z\right\| \\
& \leq\left\|\left(1-\alpha_{n}\right) x_{n}+\alpha_{n} T P\left[\beta_{n} T x_{n}+\left(1-\beta_{n}\right) x_{n}\right]-z\right\| \\
& \leq\left(1-\alpha_{n}\right)\left\|x_{n}-z\right\|+\alpha_{n}\left\|T P\left[\beta_{n} T x_{n}+\left(1-\beta_{n}\right) x_{n}\right]-z\right\| \\
& \leq\left(1-\alpha_{n}\right)\left\|x_{n}-z\right\|+\alpha_{n}\left\|P\left[\beta_{n} T x_{n}+\left(1-\beta_{n}\right) x_{n}\right]-P z\right\| \\
& \leq\left(1-\alpha_{n}\right)\left\|x_{n}-z\right\|+\alpha_{n}\left\|\beta_{n} T x_{n}+\left(1-\beta_{n}\right) x_{n}-z\right\| \\
& \leq\left(1-\alpha_{n}\right)\left\|x_{n}-z\right\|+\alpha_{n}\left[\beta_{n}\left\|T x_{n}-z\right\|+\left(1-\beta_{n}\right)\left\|x_{n}-z\right\|\right] \\
& \leq\left(1-\alpha_{n}\right)\left\|x_{n}-z\right\|+\alpha_{n}\left[\beta_{n}\left\|x_{n}-z\right\|+\left(1-\beta_{n}\right)\left\|x_{n}-z\right\|\right] \\
& \leq\left(1-\alpha_{n}\right)\left\|x_{n}-z\right\|+\alpha_{n}\left\|x_{n}-z\right\| \\
& =\left\|x_{n}-z\right\|,
\end{aligned}
$$

and thus the sequence $\left\{\left\|x_{n}-z\right\|\right\}$ is nonincreasing and bounded below. Hence we see that

$$
\lim _{n \rightarrow \infty}\left\|x_{n}-z\right\|(\equiv c)
$$

exists. If $c=0$, then the conclusion is obvious. So, we assume $c>0$. Put $y_{n}=P\left[\beta_{n} T x_{n}+\left(1-\beta_{n}\right) x_{n}\right]$ for all $n \geq 1$. Then

$$
\begin{aligned}
\left\|y_{n}-z\right\| & =\left\|P\left[\beta_{n} T x_{n}+\left(1-\beta_{n}\right) x_{n}\right]-P z\right\| \\
& \leq\left\|\beta_{n} T x_{n}+\left(1-\beta_{n}\right) x_{n}-z\right\| \\
& \leq \beta_{n}\left\|T x_{n}-z\right\|+\left(1-\beta_{n}\right)\left\|x_{n}-z\right\| \\
& \leq \beta_{n}\left\|x_{n}-z\right\|+\left(1-\beta_{n}\right)\left\|x_{n}-z\right\| \\
& =\left\|x_{n}-z\right\| .
\end{aligned}
$$

So, we have

$$
\limsup _{n \rightarrow \infty}\left\|y_{n}-z\right\| \leq c
$$

By using (6), we obtain

$$
\left\|T y_{n}-z\right\| \leq\left\|y_{n}-z\right\| \leq\left\|x_{n}-z\right\| .
$$

By using Lemma 2, we have

$$
\begin{aligned}
\left\|x_{n+1}-z\right\| & =\left\|P\left(\left(1-\alpha_{n}\right) x_{n}+\alpha_{n} T y_{n}\right)-P z\right\| \\
& \leq\left\|\left(1-\alpha_{n}\right) x_{n}+\alpha_{n} T y_{n}-z\right\| \\
& =\left\|\alpha_{n}\left(T y_{n}-z\right)+\left(1-\alpha_{n}\right)\left(x_{n}-z\right)\right\| \\
& \leq\left(\left\|x_{n}-z\right\|\right)\left[1-2 \alpha_{n}\left(1-\alpha_{n}\right) \delta_{E}\left(\frac{\left\|T y_{n}-x_{n}\right\|}{\left\|x_{n}-z\right\|}\right)\right] .
\end{aligned}
$$

Hence we obtain

$$
2 \alpha_{n}\left(1-\alpha_{n}\right)\left(\left\|x_{n}-z\right\|\right) \delta_{E}\left(\frac{\left\|T y_{n}-x_{n}\right\|}{\left\|x_{n}-z\right\|}\right) \leq\left\|x_{n}-z\right\|-\left\|x_{n+1}-z\right\| .
$$


Since

$$
2 a(1-b) \sum_{n=1}^{\infty}\left(\left\|x_{n}-z\right\|\right) \delta_{E}\left(\frac{\left\|T y_{n}-x_{n}\right\|}{\left\|x_{n}-z\right\|}\right)<\infty,
$$

and $\delta_{E}$ is strictly increasing and continuous, we obtain

$$
\lim _{n \rightarrow \infty}\left\|T y_{n}-x_{n}\right\|=0 \text {. }
$$

Since

$$
\begin{aligned}
\left\|x_{n}-z\right\| & \leq\left\|x_{n}-T y_{n}\right\|+\left\|T y_{n}-z\right\| \\
& \leq\left\|x_{n}-T y_{n}\right\|+\left\|y_{n}-z\right\|,
\end{aligned}
$$

and by (8), we obtain

$$
c \leq \liminf _{n \rightarrow \infty}\left\|y_{n}-z\right\|
$$

By using (7) and (9), we obtain

$$
\begin{aligned}
c & =\lim _{n \rightarrow \infty}\left\|y_{n}-z\right\| \\
& =\lim _{n \rightarrow \infty}\left\|P\left[\beta_{n} T x_{n}+\left(1-\beta_{n}\right) x_{n}\right]-P z\right\| \\
& \leq \lim _{n \rightarrow \infty}\left\|\beta_{n} T x_{n}+\left(1-\beta_{n}\right) x_{n}-z\right\| \\
& =\lim _{n \rightarrow \infty}\left\|\beta_{n}\left(T x_{n}-z\right)+\left(1-\beta_{n}\right)\left(x_{n}-z\right)\right\| \\
& \leq \lim _{n \rightarrow \infty}\left\{\beta_{n}\left\|T x_{n}-z\right\|+\left(1-\beta_{n}\right)\left\|x_{n}-z\right\|\right\} \\
& \leq \lim _{n \rightarrow \infty}\left\{\beta_{n}\left\|x_{n}-z\right\|+\left(1-\beta_{n}\right)\left\|x_{n}-z\right\|\right\} \\
& =\lim _{n \rightarrow \infty}\left\|x_{n}-z\right\|=c .
\end{aligned}
$$

By using $\lim \sup _{n \rightarrow \infty}\left\|T x_{n}-z\right\| \leq c$ and Lemma 1, we obtain $\lim _{n \rightarrow \infty} \| T x_{n}-$ $x_{n} \|=0$.

Theorem 2. Let $E$ be a uniformly convex Banach space satisfying Opial's condition, and let $C$ be a nonempty closed convex subset of $E$ which is also a nonexpansive retract of $E$, and let $T: C \rightarrow E$ be a quasi-nonexpansive mapping with $I-T$ demiclosed at zero. Suppose that for any $x_{1}$ in $C$, the sequence $\left\{x_{n}\right\}$ is defined by (2), where $\left\{\alpha_{n}\right\}$ and $\left\{\beta_{n}\right\}$ are chosen so that $0<a \leq \alpha_{n}, \beta_{n} \leq$ $b<1$ for all $n \geq 1$ and some $a, b \in(0,1)$. Then $\left\{x_{n}\right\}$ converges weakly to some fixed point of $T$.

Proof. For any $z \in F(T)$, by (5) in the proof of Theorem $1,\left\{x_{n}\right\}$ is bounded. Let $z_{1}$ and $z_{2}$ be two weak subsequential limits of the sequence $\left\{x_{n}\right\}$. Then we claim that the conditions $x_{n_{p}} \rightarrow z_{1}$ and $x_{n_{q}} \rightarrow z_{2}$ imply $z_{1}=z_{2} \in F(T)$. In fact, since $I-T$ demiclosed at zero and by using Theorem 1 , we have $z_{1}, z_{2} \in F(T)$. Next, we show $z_{1}=z_{2}$. If not, by Opial's condition and (5) in 
the proof of Theorem 1,

$$
\begin{aligned}
\lim _{n \rightarrow \infty}\left\|x_{n}-z_{1}\right\| & =\lim _{p \rightarrow \infty}\left\|x_{n_{p}}-z_{1}\right\| \\
& <\lim _{p \rightarrow \infty}\left\|x_{n_{p}}-z_{2}\right\| \\
& =\lim _{n \rightarrow \infty}\left\|x_{n}-z_{2}\right\|
\end{aligned}
$$

and by using similar method, we have

$$
\lim _{n \rightarrow \infty}\left\|x_{n}-z_{2}\right\|<\lim _{n \rightarrow \infty}\left\|x_{n}-z_{1}\right\| .
$$

This is a contradiction. Hence we have $z_{1}=z_{2}$. Therefore $\left\{x_{n}\right\}$ converges weakly to some fixed point of $T$.

Our Theorem 3 carries over Theorem 3.6 of Shahzad [11] to a quasi-nonexpansive mapping.

Theorem 3. Let $E$ be a uniformly convex Banach space, and let $C$ be a nonempty closed convex subset of $E$ which is also a nonexpansive retract of $E$, and let $T: C \rightarrow E$ be a quasi-nonexpansive mapping, and $T$ satisfies Condition A. Suppose that for any $x_{1}$ in $C$, the sequence $\left\{x_{n}\right\}$ is defined by (2), where $\left\{\alpha_{n}\right\}$ and $\left\{\beta_{n}\right\}$ are chosen so that $0<a \leq \alpha_{n}, \beta_{n} \leq b<1$ for all $n \geq 1$ and some $a, b \in(0,1)$. Then $\left\{x_{n}\right\}$ converges strongly to some fixed point of $T$.

Proof. By using Condition A, we obtain

$$
f\left(d\left(x_{n}, F(T)\right)\right) \leq\left\|T x_{n}-x_{n}\right\|
$$

for all $n \geq 1$. By using (4) in the proof of Theorem 1, we obtain

$$
\inf _{z \in F(T)}\left\|x_{n+1}-z\right\| \leq \inf _{z \in F(T)}\left\|x_{n}-z\right\| .
$$

Thus $\lim _{n \rightarrow \infty} d\left(x_{n}, F(T)\right)(\equiv k)$ exists. We first claim that $\lim _{n \rightarrow \infty} d\left(x_{n}, F(T)\right)$ $=0$. In fact, assume that $k=\lim _{n \rightarrow \infty} d\left(x_{n}, F(T)\right)>0$. Then we can choose $n_{0} \in N$ such that $0<\frac{k}{2}<d\left(x_{n}, F(T)\right)$ for all $n \geq n_{0}$. By using Condition $\mathbf{A}$ and Theorem 1, we obtain

$$
0<f\left(\frac{k}{2}\right) \leq f\left(d\left(x_{n}, F(T)\right)\right) \leq\left\|T x_{n}-x_{n}\right\| \rightarrow 0
$$

as $n \rightarrow \infty$. This is a contradiction. So, we obtain $k=0$. Next, we claim that $\left\{x_{n}\right\}$ is a Cauchy sequence. Let $\epsilon>0$ be given. Since $\lim _{n \rightarrow \infty} d\left(x_{n}, F(T)\right)=0$, there exists $n_{0} \in N$ such that for all $n \geq n_{0}$, we obtain

$$
d\left(x_{n}, F(T)\right)<\frac{\epsilon}{2}
$$

Let $n, m \geq n_{0}$ and $p \in F(T)$. Then, from (4) in the proof of Theorem 1 , we obtain

$$
\begin{aligned}
\left\|x_{n}-x_{m}\right\| & \leq\left\|x_{n}-p\right\|+\left\|x_{m}-p\right\| \\
& \leq 2\left[\left\|x_{n_{0}}-p\right\|\right] .
\end{aligned}
$$

Taking the infimum over all $p \in F(T)$ on both sides and by (10), we obtain

$$
\left\|x_{n}-x_{m}\right\| \leq 2\left[d\left(x_{n_{0}}, F(T)\right)\right]<\epsilon
$$


for all $n, m \geq n_{0}$. This implies that $\left\{x_{n}\right\}$ is a Cauchy sequence. Let $\lim _{n \rightarrow \infty} x_{n}$ $=q$. Then $d(q, F(T))=0$. Since $F(T)$ is closed, we obtain $q \in F(T)$. Hence $\left\{x_{n}\right\}$ converges strongly to some fixed point of $T$.

Theorem 4. Let $E$ be a uniformly convex Banach space, and let $C$ be a nonempty closed convex subset of $E$ which is also a nonexpansive retract of $E$, and let $T: C \rightarrow E$ be a continuous quasi-nonexpansive mapping, and let $T(C)$ be contained in a compact subset of $E$. Suppose that for any $x_{1}$ in $C$, the sequence $\left\{x_{n}\right\}$ is defined by $(2)$, where $\left\{\alpha_{n}\right\}$ and $\left\{\beta_{n}\right\}$ are chosen so that $0<a \leq \alpha_{n}, \beta_{n} \leq b<1$ for all $n \geq 1$ and some $a, b \in(0,1)$. Then $\left\{x_{n}\right\}$ converges strongly to some fixed point of $T$.

Proof. Since $\left\{x_{n}\right\}$ is well-defined and the closure of $T(C)$ is compact, there exists a subsequence $\left\{T x_{n_{i}}\right\}$ of the sequence $\left\{T x_{n}\right\}$ such that $\left\{T x_{n_{i}}\right\} \rightarrow z$. By Theorem 1, we can choose a subsequence $\left\{x_{n_{i}}\right\}$ of $\left\{x_{n}\right\}$ such that $\left\{x_{n_{i}}\right\}$ converges strongly to $z$. Thus, by using Theorem 1 and the continuity of $T$, we obtain $z \in F(T)$. From (5) in the proof of Theorem 1, we obtain $\lim _{n \rightarrow \infty}\left\|x_{n}-z\right\|=0$.

Theorem 5. Let $E$ be a uniformly convex Banach space, and let $C$ be a nonempty closed convex subset of $E$, and let $T: C \rightarrow C$ be a quasi-nonexpansive mapping. Suppose that for any $x_{1}$ in $C$, the sequence $\left\{x_{n}\right\}$ is defined by

$$
x_{n+1}=\alpha_{n} x_{n}+\beta_{n} T x_{n}+\gamma_{n} u_{n},
$$

where $\left\{\alpha_{n}\right\},\left\{\beta_{n}\right\}$ and $\left\{\gamma_{n}\right\}$ in $[0,1]$ with $\sum_{n=1}^{\infty} \beta_{n}\left(1-\beta_{n}\right)=\infty$, and $\left\{u_{n}\right\}$ is a bounded sequence in $C$ such that (i) $\alpha_{n}+\beta_{n}+\gamma_{n}=1$ for all $n \geq 1$, (ii) $\sum_{n=1}^{\infty} \gamma_{n}<\infty$. Then $\liminf _{n \rightarrow \infty}\left\|T x_{n}-x_{n}\right\|=0$.

Proof. For a fixed $z \in F(T)$, since $\left\{u_{n}\right\}$ is bounded in $C$, let

$$
M:=\sup _{n \geq 1}\left\|u_{n}-z\right\|<\infty .
$$

From

$$
\begin{aligned}
\left\|x_{n+1}-z\right\| & =\left\|\alpha_{n} x_{n}+\beta_{n} T x_{n}+\gamma_{n} u_{n}-z\right\| \\
& \leq \alpha_{n}\left\|x_{n}-z\right\|+\beta_{n}\left\|T x_{n}-z\right\|+\gamma_{n}\left\|u_{n}-z\right\| \\
& \leq \alpha_{n}\left\|x_{n}-z\right\|+\beta_{n}\left\|x_{n}-z\right\|+\gamma_{n}\left\|u_{n}-z\right\| \\
& =\left(1-\gamma_{n}\right)\left\|x_{n}-z\right\|+\gamma_{n}\left\|u_{n}-z\right\| \\
& \leq\left\|x_{n}-z\right\|+\gamma_{n} M
\end{aligned}
$$

and Lemma 3, we readily see that

$$
\lim _{n \rightarrow \infty}\left\|x_{n}-z\right\|(\equiv c)
$$

exists. If $c=0$, then the conclusion is obvious. So, we assume $c>0$. Since

$$
\begin{aligned}
\left\|T x_{n}-z+\gamma_{n}\left(u_{n}-x_{n}\right)\right\| & \leq\left\|T x_{n}-z\right\|+\gamma_{n}\left\|u_{n}-x_{n}\right\| \\
& \leq\left\|x_{n}-z\right\|+\gamma_{n} M^{\prime},
\end{aligned}
$$


where $M^{\prime}=\sup _{n \geq 1}\left\|u_{n}-x_{n}\right\|<\infty$ and

$$
\left\|x_{n}-z+\gamma_{n}\left(u_{n}-x_{n}\right)\right\| \leq\left\|x_{n}-z\right\|+\gamma_{n} M^{\prime}
$$

and by Lemma 2, we have

$$
\begin{aligned}
& \left\|x_{n+1}-z\right\| \\
= & \left\|\alpha_{n} x_{n}+\beta_{n} T x_{n}+\gamma_{n} u_{n}-z\right\| \\
= & \left\|\alpha_{n}\left(x_{n}-z\right)+\beta_{n}\left(T x_{n}-z\right)+\gamma_{n}\left(u_{n}-z\right)\right\| \\
= & \| \beta_{n}\left(T x_{n}-z\right)+\alpha_{n}\left(x_{n}-z\right)+\gamma_{n}\left(u_{n}-x_{n}+x_{n}-z\right) \\
& \quad+\beta_{n} \gamma_{n}\left(u_{n}-x_{n}\right)-\beta_{n} \gamma_{n}\left(u_{n}-x_{n}\right) \| \\
= & \| \beta_{n}\left(T x_{n}-z\right)+\left(1-\beta_{n}\right)\left(x_{n}-z\right)+\gamma_{n}\left(u_{n}-x_{n}\right) \\
& \quad+\beta_{n} \gamma_{n}\left(u_{n}-x_{n}\right)-\beta_{n} \gamma_{n}\left(u_{n}-x_{n}\right) \| \\
= & \| \beta_{n}\left(T x_{n}-z\right)+\beta_{n} \gamma_{n}\left(u_{n}-x_{n}\right)+\left(1-\beta_{n}\right)\left(x_{n}-z\right) \\
& \quad+\left(1-\beta_{n}\right) \gamma_{n}\left(u_{n}-x_{n}\right) \| \\
= & \left\|\beta_{n}\left(T x_{n}-z+\gamma_{n}\left(u_{n}-x_{n}\right)\right)+\left(1-\beta_{n}\right)\left(x_{n}-z+\gamma_{n}\left(u_{n}-x_{n}\right)\right)\right\| \\
\leq & \left(\left\|x_{n}-z\right\|+\gamma_{n} M^{\prime}\right)\left[1-2 \beta_{n}\left(1-\beta_{n}\right) \delta_{E}\left(\frac{\left\|T x_{n}-x_{n}\right\|}{\left\|x_{n}-z\right\|+\gamma_{n} M^{\prime}}\right)\right] .
\end{aligned}
$$

Hence we obtain

$$
\begin{aligned}
& 2 \beta_{n}\left(1-\beta_{n}\right)\left(\left\|x_{n}-z\right\|+\gamma_{n} M^{\prime}\right) \delta_{E}\left(\frac{\left\|T x_{n}-x_{n}\right\|}{\left\|x_{n}-z\right\|+\gamma_{n} M^{\prime}}\right) \\
\leq & \left\|x_{n}-z\right\|-\left\|x_{n+1}-z\right\|+\gamma_{n} M^{\prime} .
\end{aligned}
$$

Since

$$
2 \sum_{n=1}^{\infty} \beta_{n}\left(1-\beta_{n}\right)\left(\left\|x_{n}-z\right\|+\gamma_{n} M^{\prime}\right) \delta_{E}\left(\frac{\left\|T x_{n}-x_{n}\right\|}{\left\|x_{n}-z\right\|+\gamma_{n} M^{\prime}}\right)<\infty,
$$

and $\delta_{E}$ is strictly increasing and continuous, we obtain

$$
\liminf _{n \rightarrow \infty}\left\|T x_{n}-x_{n}\right\|=0 .
$$

Theorem 6. Let $E$ be a uniformly convex Banach space. Let $C$ be a nonempty closed convex subset of $E$ and let $T: C \rightarrow C$ be a quasi-nonexpansive mapping satisfying Condition A. Suppose that for any $x_{1}$ in $C$, the sequence $\left\{x_{n}\right\}$ is defined by

$$
x_{n+1}=\alpha_{n} x_{n}+\beta_{n} T x_{n}+\gamma_{n} u_{n},
$$

where $\left\{\alpha_{n}\right\},\left\{\beta_{n}\right\}$ and $\left\{\gamma_{n}\right\}$ in $[0,1]$ with $\sum_{n=1}^{\infty} \beta_{n}\left(1-\beta_{n}\right)=\infty$, and $\left\{u_{n}\right\}$ is a bounded sequence in $C$ such that (i) $\alpha_{n}+\beta_{n}+\gamma_{n}=1$ for all $n \geq 1$, (ii) $\sum_{n=1}^{\infty} \gamma_{n}<\infty$. Then $\left\{x_{n}\right\}$ converges strongly to some fixed point of $T$.

Proof. By Theorem 5, there exists a subsequence $\left\{x_{n_{k}}\right\}$ of the sequence $\left\{x_{n}\right\}$ such that

$$
\lim _{k \rightarrow \infty}\left\|T x_{n_{k}}-x_{n_{k}}\right\|=0
$$


By Condition A, we obtain

$$
f\left(d\left(x_{n}, F(T)\right)\right) \leq\left\|T x_{n}-x_{n}\right\|
$$

for all $n \geq 1$. As in the proof of Theorem 5 , we obtain

$$
\left\|x_{n+1}-z\right\| \leq\left\|x_{n}-z\right\|+\gamma_{n} M .
$$

Thus

$$
\inf _{z \in \mathbf{F}}\left\|x_{n+1}-z\right\| \leq \inf _{z \in \mathbf{F}}\left\|x_{n}-z\right\|+\gamma_{n} M
$$

By Lemma 3, we see that $\lim _{n \rightarrow \infty} d\left(x_{n}, F(T)\right)(\equiv r)$ exists. We first claim that $\lim _{n \rightarrow \infty} d\left(x_{n}, F(T)\right)=0$. In fact, assume that $r=\lim _{n \rightarrow \infty} d\left(x_{n}, F(T)\right)>0$. Then we can choose $n_{0} \in N$ such that $0<\frac{r}{2}<d\left(x_{n}, F(T)\right)$ for all $n \geq n_{0}$. By using Condition $\mathbf{A}$ and (12), we obtain

$$
0<f\left(\frac{r}{2}\right) \leq f\left(d\left(x_{n_{k}}, F(T)\right)\right) \leq\left\|T x_{n_{k}}-x_{n_{k}}\right\| \rightarrow 0
$$

as $k \rightarrow \infty$. This is a contradiction. So, we obtain $r=0$. Next, we claim that $\left\{x_{n}\right\}$ is a Cauchy sequence. Let $\epsilon>0$ be given. Since $\lim _{n \rightarrow \infty} d\left(x_{n}, F(T)\right)=0$ and $\sum_{n=1}^{\infty} \gamma_{n}<\infty$, there exists $n_{0} \in N$ such that for all $n \geq n_{0}$, we obtain

$$
d\left(x_{n}, F(T)\right)<\frac{\epsilon}{4} \quad \text { and } \quad \sum_{i=n_{0}}^{\infty} \gamma_{i}<\frac{\epsilon}{4(M+1)} .
$$

Let $n, m \geq n_{0}$ and $p \in F(T)$. Then, by using (13), we obtain

$$
\begin{aligned}
\left\|x_{n}-x_{m}\right\| & \leq\left\|x_{n}-p\right\|+\left\|x_{m}-p\right\| \\
& \leq\left\|x_{n_{0}}-p\right\|+\sum_{i=n_{0}}^{n-1} \gamma_{i} M+\left\|x_{n_{0}}-p\right\|+\sum_{i=n_{0}}^{m-1} \gamma_{i} M \\
& \leq 2\left[\left\|x_{n_{0}}-p\right\|+\sum_{i=n_{0}}^{\infty} \gamma_{i}(M+1)\right] .
\end{aligned}
$$

Taking the infimum over all $p \in F(T)$ on both sides and by using (14), we obtain

$$
\begin{aligned}
\left\|x_{n}-x_{m}\right\| & \leq 2\left[d\left(x_{n_{0}}, F(T)\right)+\sum_{i=n_{0}}^{\infty} \gamma_{i}(M+1)\right] \\
& <2\left(\frac{\epsilon}{4}+\frac{\epsilon}{4}\right)=\epsilon
\end{aligned}
$$

for all $n, m \geq n_{0}$. This implies that $\left\{x_{n}\right\}$ is a Cauchy sequence. Let $\lim _{n \rightarrow \infty} x_{n}$ $=q$. Then $d(q, F(T))=0$. Since $F(T)$ is closed, we obtain $q \in F(T)$. Hence $\left\{x_{n}\right\}$ converges strongly to some fixed point of $T$.

As a direct consequence, taking $\gamma_{n}=0$ for all $n \geq 1$ in Theorem 6 , we obtain the following result, which improves Theorem 2 of Senter-Dotson [10] under much less restriction on the iterative parameter $\left\{\alpha_{n}\right\}$. 
Theorem 7. Let $E$ be a uniformly convex Banach space, and let $C$ be a nonempty closed convex subset of $E$, and let $T: C \rightarrow C$ be a quasi-nonexpansive mapping satisfying Condition A. Suppose that for any $x_{1} \in C$, the sequence $\left\{x_{n}\right\}$ is given by

$$
x_{n+1}=\left(1-\alpha_{n}\right) x_{n}+\alpha_{n} T x_{n}
$$

for all $n \geq 1$, where $\left\{\alpha_{n}\right\}$ in $[0,1]$ is chosen so that $\sum_{n=1}^{\infty} \alpha_{n}\left(1-\alpha_{n}\right)=\infty$. Then $\left\{x_{n}\right\}$ converges strongly to some fixed point of $T$.

Corollary 1 ([10]). Let $E$ be a uniformly convex Banach space, and let $C$ be a nonempty closed convex subset of $E$, and let $T: C \rightarrow C$ be a quasi-nonexpansive mapping satisfying Condition A. Suppose that for any $x_{1} \in C$, the sequence $\left\{x_{n}\right\}$ is given by

$$
x_{n+1}=\left(1-\alpha_{n}\right) x_{n}+\alpha_{n} T x_{n}
$$

for all $n \geq 1$, where $\left\{\alpha_{n}\right\}$ in $[0,1]$ is chosen so that $\alpha_{n} \in[a, b]$ for all $n \geq 1$ and some $a, b \in(0,1)$. Then $\left\{x_{n}\right\}$ converges strongly to some fixed point of $T$.

Theorem 8. Let $E$ be a uniformly convex Banach space. Let $C$ be a nonempty closed convex subset of $E$ and let $T, S: C \rightarrow C$ be two quasi-nonexpansive mappings satisfying Condition $\mathbf{D}$ with $\mathbf{F}=F(T) \bigcap F(S) \neq \emptyset$. Suppose that for any $x_{1}$ in $C$, the sequence $\left\{x_{n}\right\}$ is defined by (3), where $\left\{\alpha_{n}\right\},\left\{\beta_{n}\right\}$ in $[0,1]$ with the restriction that $\sum_{n=1}^{\infty} \beta_{n}\left(1-\beta_{n}\right)=\infty$. Then $\left\{x_{n}\right\}$ converges strongly to a common fixed point of $T$ and $S$.

Proof. For a fixed $z \in \mathbf{F}$, since $\left\{u_{n}\right\}$ and $\left\{v_{n}\right\}$ are bounded in $C$, let

$$
M:=\sup _{n \geq 1}\left\|u_{n}-z\right\| \vee \sup _{n \geq 1}\left\|v_{n}-z\right\|<\infty .
$$

From

$$
\begin{aligned}
\left\|T y_{n}-z\right\| & \leq\left\|y_{n}-z\right\| \\
& =\left\|\alpha_{n}^{\prime} S x_{n}+\beta_{n}^{\prime} T x_{n}+\gamma_{n}^{\prime} v_{n}-z\right\| \\
& \leq \alpha_{n}^{\prime}\left\|S x_{n}-z\right\|+\beta_{n}^{\prime}\left\|T x_{n}-z\right\|+\gamma_{n}^{\prime}\left\|v_{n}-z\right\| \\
& \leq \alpha_{n}^{\prime}\left\|x_{n}-z\right\|+\beta_{n}^{\prime}\left\|x_{n}-z\right\|+\gamma_{n}^{\prime}\left\|v_{n}-z\right\| \\
& =\left(1-\gamma_{n}^{\prime}\right)\left\|x_{n}-z\right\|+\gamma_{n}^{\prime}\left\|v_{n}-z\right\| \\
& \leq\left\|x_{n}-z\right\|+\gamma_{n}^{\prime} M,
\end{aligned}
$$

we have

$$
\begin{aligned}
\left\|x_{n+1}-z\right\| & =\left\|\alpha_{n} S x_{n}+\beta_{n} T y_{n}+\gamma_{n} u_{n}-z\right\| \\
& \leq \alpha_{n}\left\|S x_{n}-z\right\|+\beta_{n}\left\|T y_{n}-z\right\|+\gamma_{n}\left\|u_{n}-z\right\| \\
& \leq \alpha_{n}\left\|x_{n}-z\right\|+\beta_{n}\left\{\left\|x_{n}-z\right\|+\gamma_{n}^{\prime} M\right\}+\gamma_{n}\left\|u_{n}-z\right\| \\
& \leq\left(1-\gamma_{n}\right)\left\|x_{n}-z\right\|+\gamma_{n}^{\prime} M+\gamma_{n} M \\
& \leq\left\|x_{n}-z\right\|+\left(\gamma_{n}^{\prime}+\gamma_{n}\right) M
\end{aligned}
$$


By using Lemma 3, we readily see that

$$
\lim _{n \rightarrow \infty}\left\|x_{n}-z\right\|(\equiv d)
$$

exists. Without loss of generality, we assume $d>0$. By using (15), we obtain

$$
\begin{aligned}
\left\|T y_{n}-z+\gamma_{n}\left(u_{n}-S x_{n}\right)\right\| & \leq\left\|T y_{n}-z\right\|+\gamma_{n}\left\|u_{n}-S x_{n}\right\| \\
& \leq\left\|x_{n}-z\right\|+\gamma_{n}^{\prime} M+\gamma_{n} M^{\prime \prime},
\end{aligned}
$$

where $M^{\prime \prime}=\sup _{n \geq 1}\left\|u_{n}-S x_{n}\right\|<\infty$ and

$$
\begin{aligned}
\left\|S x_{n}-z+\gamma_{n}\left(u_{n}-S x_{n}\right)\right\| & \leq\left\|S x_{n}-z\right\|+\gamma_{n}\left\|u_{n}-S x_{n}\right\| \\
& \leq\left\|x_{n}-z\right\|+\gamma_{n} M^{\prime \prime} \\
& \leq\left\|x_{n}-z\right\|+\gamma_{n}^{\prime} M+\gamma_{n} M^{\prime \prime} .
\end{aligned}
$$

Thus by Lemma 2, we have

$$
\begin{aligned}
& \left\|x_{n+1}-z\right\| \\
= & \left\|\alpha_{n} S x_{n}+\beta_{n} T y_{n}+\gamma_{n} u_{n}-z\right\| \\
= & \left\|\alpha_{n}\left(S x_{n}-z\right)+\beta_{n}\left(T y_{n}-z\right)+\gamma_{n}\left(u_{n}-z\right)\right\| \\
= & \| \beta_{n}\left(T y_{n}-z\right)+\alpha_{n}\left(S x_{n}-z\right)+\gamma_{n}\left(u_{n}-S x_{n}+S x_{n}-z\right) \\
& \quad+\beta_{n} \gamma_{n}\left(u_{n}-S x_{n}\right)-\beta_{n} \gamma_{n}\left(u_{n}-S x_{n}\right) \| \\
= & \| \beta_{n}\left(T y_{n}-z\right)+\left(1-\beta_{n}\right)\left(S x_{n}-z\right)+\gamma_{n}\left(u_{n}-S x_{n}\right) \\
& \quad+\beta_{n} \gamma_{n}\left(u_{n}-S x_{n}\right)-\beta_{n} \gamma_{n}\left(u_{n}-S x_{n}\right) \| \\
= & \| \beta_{n}\left(T y_{n}-z\right)+\beta_{n} \gamma_{n}\left(u_{n}-S x_{n}\right)+\left(1-\beta_{n}\right)\left(S x_{n}-z\right) \\
& \quad+\left(1-\beta_{n}\right) \gamma_{n}\left(u_{n}-S x_{n}\right) \| \\
= & \left\|\beta_{n}\left(T y_{n}-z+\gamma_{n}\left(u_{n}-S x_{n}\right)\right)+\left(1-\beta_{n}\right)\left(S x_{n}-z+\gamma_{n}\left(u_{n}-S x_{n}\right)\right)\right\| \\
\leq & \left(\left\|x_{n}-z\right\|+\gamma_{n}^{\prime} M+\gamma_{n} M^{\prime \prime}\right)\left[1-2 \beta_{n}\left(1-\beta_{n}\right) \delta_{E}\left(\frac{\left\|T y_{n}-S x_{n}\right\|}{\left\|x_{n}-z\right\|+\gamma_{n}^{\prime} M+\gamma_{n} M^{\prime \prime}}\right)\right] .
\end{aligned}
$$

Hence we obtain

$$
\begin{aligned}
& 2 \beta_{n}\left(1-\beta_{n}\right)\left(\left\|x_{n}-z\right\|+\gamma_{n}^{\prime} M+\gamma_{n} M^{\prime \prime}\right) \delta_{E}\left(\frac{\left\|T y_{n}-S x_{n}\right\|}{\left\|x_{n}-z\right\|+\gamma_{n}^{\prime} M+\gamma_{n} M^{\prime \prime}}\right) \\
\leq & \left\|x_{n}-z\right\|-\left\|x_{n+1}-z\right\|+\gamma_{n}^{\prime} M+\gamma_{n} M^{\prime \prime} .
\end{aligned}
$$

Since

$$
2 \sum_{n=1}^{\infty} \beta_{n}\left(1-\beta_{n}\right)\left(\left\|x_{n}-z\right\|+\gamma_{n}^{\prime} M+\gamma_{n} M^{\prime \prime}\right) \delta_{E}\left(\frac{\left\|T y_{n}-S x_{n}\right\|}{\left\|x_{n}-z\right\|+\gamma_{n}^{\prime} M+\gamma_{n} M^{\prime \prime}}\right)<\infty
$$

and $\delta_{E}$ is strictly increasing and continuous, we obtain

$$
\liminf _{n \rightarrow \infty}\left\|T y_{n}-S x_{n}\right\|=0 .
$$

By using (16) and Lemma 3, we see that

$$
\lim _{n \rightarrow \infty} d\left(x_{n}, \mathbf{F}\right)
$$


exists. By using Condition D, (17) and taking lim inf on both sides, we obtain

$$
\liminf _{n \rightarrow \infty} f\left(d\left(x_{n}, \mathbf{F}\right)\right) \leq \liminf _{n \rightarrow \infty}\left\|S x_{n}-T y_{n}\right\| \rightarrow 0
$$

as $n \rightarrow \infty$. From the Condition D, (18) and (19), we obtain $\lim _{n \rightarrow \infty} d\left(x_{n}, \mathbf{F}\right)=$ 0 . By using similar method in the proof of Theorem $6,\left\{x_{n}\right\}$ converges strongly to a common fixed point of $T$ and $S$.

As a direct consequence, taking $\gamma_{n}=0$ for all $n \geq 1$ in Theorem 8 , we obtain the following result, which improves Theorem 1 of Ghosh-Debnath [3] under much less restriction on the iterative parameter $\left\{\alpha_{n}\right\}$.

Theorem 9. Let $E$ be a uniformly convex Banach space. Let $C$ be a nonempty closed convex subset of $E$ and let $T, S: C \rightarrow C$ be two quasi-nonexpansive mappings satisfying Condition $\mathbf{C}$ with $\mathbf{F}=F(T) \bigcap F(S) \neq \emptyset$. Suppose that for any $x_{1}$ in $C$, the sequences $\left\{x_{n}\right\}$ and $\left\{y_{n}\right\}$ are defined by

$$
x_{n+1}=\left(1-\alpha_{n}\right) S x_{n}+\alpha_{n} T y_{n}, \quad y_{n}=\left(1-\beta_{n}\right) S x_{n}+\beta_{n} T x_{n},
$$

where $\left\{\alpha_{n}\right\},\left\{\beta_{n}\right\}$ in $[0,1]$ with the restriction that $\sum_{n=1}^{\infty} \alpha_{n}\left(1-\alpha_{n}\right)=\infty$. Then $\left\{x_{n}\right\}$ converges strongly to a common fixed point of $T$ and $S$.

Corollary 2 ([3]). Let $E$ be a uniformly convex Banach space. Let $C$ be a nonempty closed convex subset of $E$ and let $T, S: C \rightarrow C$ be two quasinonexpansive mappings satisfying Condition $\mathbf{C}$ with $\mathbf{F}=F(T) \bigcap F(S) \neq \emptyset$. Suppose that for any $x_{1}$ in $C$, the sequences $\left\{x_{n}\right\}$ and $\left\{y_{n}\right\}$ are defined by

$$
x_{n+1}=\left(1-\alpha_{n}\right) S x_{n}+\alpha_{n} T y_{n}, \quad y_{n}=\left(1-\beta_{n}\right) S x_{n}+\beta_{n} T x_{n},
$$

where $\left\{\alpha_{n}\right\}$ and $\left\{\beta_{n}\right\}$ are chosen so that $0<a \leq \alpha_{n} \leq b<1,0 \leq \beta_{n} \leq b<1$ for all $n \geq 1$ and some $a, b \in(0,1)$. Then $\left\{x_{n}\right\}$ converges strongly to a common fixed point of $T$ and $S$.

Corollary 3 ([6]). Let $E$ be a uniformly convex Banach space. Let $C$ be a nonempty closed convex subset of $E$ and let $T: C \rightarrow C$ be a quasi-nonexpansive mappings satisfying Condition B. Suppose that for any $x_{1}$ in $C$, the sequence $\left\{x_{n}\right\}$ is defined by (1), where $\left\{\alpha_{n}\right\}$ and $\left\{\beta_{n}\right\}$ are chosen so that $0<a \leq \alpha_{n} \leq$ $b<1,0 \leq \beta_{n} \leq b<1$ for all $n \geq 1$ and some $a, b \in(0,1)$. Then $\left\{x_{n}\right\}$ converges strongly to a fixed point of $T$.

Remark 1. If $\left\{\alpha_{n}\right\}$ is bounded away from both 0 and 1, i.e., $a \leq \alpha_{n} \leq b$ for all $n \geq 1$ and some $a, b \in(0,1)$, then $\sum_{n=1}^{\infty} \alpha_{n}\left(1-\alpha_{n}\right)=\infty$ holds. However, the converse is not true. For example, consider $\alpha_{n}=\frac{1}{n}$.

Remark 2. The concept of quasi-nonexpansive mapping is more general than that of nonexpansive mapping.

We give two examples of quasi-nonexpansive mappings which are not nonexpansive mappings. 
Example 1. Let $E=[-\pi, \pi]$ and let $T$ be defined by

$$
T x=x \cos x
$$

for each $x \in E$. Clearly $F(T)=\{0\} . T$ is a quasi-nonexpansive mapping since if $x \in E$ and $z=0$, then

$$
\|T x-z\|=\|T x-0\|=|x||\cos x| \leq|x|=\|x-z\| .
$$

But it is not a nonexpansive mapping. In fact, if we take $x=\frac{\pi}{2}$ and $y=\pi$, then

$$
\|T x-T y\|=\left\|\frac{\pi}{2} \cos \frac{\pi}{2}-\pi \cos \pi\right\|=\pi,
$$

whereas,

$$
\|x-y\|=\left\|\frac{\pi}{2}-\pi\right\|=\frac{\pi}{2} .
$$

Example 2 (cf. [2]). Let $E=\mathbb{R}$ and let $T$ be defined by

$$
\begin{aligned}
T x & =\frac{x}{2} \cos \frac{1}{x}, & & x \neq 0, \\
& =0, & & x=0 .
\end{aligned}
$$

If $x \neq 0$ and $T x=x$, then $x=\frac{x}{2} \cos \frac{1}{x}$. Thus $2=\cos \frac{1}{x}$. This is not hold. $T$ is a quasi-nonexpansive mapping since if $x \in E$ and $z=0$, then

$$
\|T x-z\|=\|T x-0\|=\left|\frac{x}{2}\right|\left|\cos \frac{1}{x}\right| \leq \frac{|x|}{2}<|x|=\|x-z\| .
$$

But it is not a nonexpansive mapping. In fact, if we take $x=\frac{2}{3 \pi}$ and $y=\frac{1}{\pi}$, then

whereas,

$$
\|T x-T y\|=\left\|\frac{1}{3 \pi} \cos \frac{3 \pi}{2}-\frac{1}{2 \pi} \cos \pi\right\|=\frac{1}{2 \pi},
$$

$$
\|x-y\|=\left\|\frac{2}{3 \pi}-\frac{1}{\pi}\right\|=\frac{1}{3 \pi} .
$$

Acknowledgements. The author would like to express my sincere appreciation to Professor T. H. Kim for useful suggestions that improved the content of this manuscript.

\section{References}

[1] F. E. Browder, Semicontractive and semiaccretive nonlinear mappings in Banach spaces, Bull. Amer. Math. Soc. 74 (1968), 660-665.

[2] W. G. Dotson, On the Mann iterative process, Trans. Amer. Math. Soc. 149 (1970), $65-73$.

[3] M. K. Ghosh and L. Debnath, Approximating common fixed points of families of quasinonexpansive mappings, Internat. J. Math. Math. Sci. 18 (1995), no. 2, 287-292.

[4] C. W. Groetsch, A note on segmenting Mann iterates, J. Math. Anal. Appl. 40 (1972), 369-372.

[5] S. Ishikawa, Fixed points by a new iteration method, Proc. Amer. Math. Soc. 44 (1974), 147-150. 
[6] M. Maiti and M. K. Ghosh, Approximating fixed points by Ishikawa iterates, Bull. Austral. Math. Soc. 40 (1989), no. 1, 113-117.

[7] W. R. Mann, Mean value methods in iteration, Proc. Amer. Math. Soc. 4 (1953), 506510.

[8] Z. Opial, Weak convergence of the sequence of successive approximations for nonexpansive mappings, Bull. Amer. Math. Soc. 73 (1967), 591-597.

[9] J. Schu, Weak and strong convergence to fixed points of asymptotically nonexpansive mappings, Bull. Austral. Math. Soc. 43 (1991), no. 1, 153-159.

[10] H. F. Senter and W. G. Dotson, Approximating fixed points of nonexpansive mappings, Proc. Amer. Math. Soc. 44 (1974), 375-380.

[11] N. Shahzad, Approximating fixed points of non-self nonexpansive mappings in Banach spaces, Nonlinear Anal. 61 (2005), no. 6, 1031-1039.

[12] K. K. Tan and H. K. Xu, Approximating fixed points of nonexpansive mappings by the Ishikawa Iteration process, J. Math. Anal. Appl. 178 (1993), no. 2, 301-308.

[13] Y. Xu, Ishikawa and Mann iterative processes with errors for nonlinear strongly accretive operator equations, J. Math. Anal. Appl. 224 (1998), no. 1, 91-101.

Department of Applied Mathematics

Pukyong National University

Pusan 608-737, Korea

E-mail address: kimge@pknu.ac.kr 